\title{
ANÁLISE DA ORGANIZAÇÃO SOCIAL ATRAVÉS DOS QUILOMBOS E FAVELAS NA PERSPECTIVA DA OBRA BECOS DE MEMÓRIA DA CONCEIÇÃO EVARISTO E SUA RELAÇÃO COM O FUTEBOL
}

\author{
ANALYSIS OF SOCIAL ORGANIZATION THROUGH QUILOMBOS AND \\ FAVELAS FROM THE PERSPECTIVE OF THE WORK BECOS DE MEMÓRIA DA \\ CONCEIÇÃO EVARISTO AND ITS RELATIONSHIP WITH FOOTBALL
}

\author{
Regis Fernando Freitas da Silva ${ }^{1}$
}

RESUMO: Buscando analisar a organização social brasileira através da obra "Becos da Memória" (2006), essa pesquisa optou por aproximar conexões entre o quilombo, os processos de favelamento e as suas raízes com a história do futebol no Brasil. Em locais onde a violência e a exclusão urbana são riscos predominantes, a memória e a identidade de uma comunidade racializada se percebe através das práticas inclusivas do futebol como esporte, e também, como meio de ascensão social. O futebol e a "Liga da Canela preta" distinguem bem a autonomia dessas comunidades. Para além disso, ajudam a manter laços de afeto e de reconhecimento com o que podem representar, com novas formas de pensar e de reproduzir ações, em meio a espaços urbanos, historicamente, marcados por períodos de violência e de desterritorialização cultural. Os processos de dizimação do quilombo são um exemplo de como a dialética da exclusão é presente dentro das favelas brasileiras e periferias do sul global, e de como essas comunidades negras vêm sofrendo com as novas formas de extermínio da sua população. $O$ futebol acaba exercendo possiblidades de mediar laços afetivos, culturais e econômicos, de grande importância social para a política. Essas vivências buscam trazer a reflexão de um pensar além do que se reproduz sobre esses ambientes sociais.

Palavra-chave: Urbanização. Quilombo. Favela. Periferia. Futebol.

ABSTRACT: Seeking to analyze a Brazilian social organization through the work "Becos da Memória" (2006), this research opted for approximate connections between quilombos, the development processes and their roots with a football history in Brazil. In places where violence and urban exclusion are prevalent risks, the memory and identity of a racial community are perceived through inclusive practices of football as a sport, and also as a means of social ascension. Football and the "Liga da Canela Preta" clearly distinguish the autonomy of these communities. In addition, it helps to maintain

\footnotetext{
${ }^{I}$ Mestre em Direito pela Universidade La Salle (2021), possui graduação em Direito pela Universidade do Vale do Rio dos Sinos (2013) e pós-graduação em Direito Desportivo e Gestão no Esporte pela Faculdade de Tributação (2019).E-mail: regisfernandosilva@gmail.com.
} 
the effects of affection and recognition with which it can exhibit, with new ways of thinking and reproducing, in the midst of urban spaces, historically marked by variations in violence and cultural dererritorialization. Quilombo decimation processes are an example of how the dialectic of exclusion of Brazilian favelas and peripheries in the global world suffers from the new forms of extermination of its population. Football ends up exercising one of these possibilities to mediate those affected, cultural and economic, of great importance for black communities. These bus experiences bring a reflection on a thought beyond what is reproduced on these social environments.

Keywords: Urbanization. Quilombo. Favela. Periphery. Soccer.

\section{INTRODUÇÃO}

O presente artigo busca analisar organização social brasileira utilizando a obra "Becos da Memória”, da autora Conceição Evaristo², para retratar o entusiasmo na constituição das primeiras favelas e a forma como a população negra esteve, historicamente, localizada durante esses processos de ocupação. Passaremos a tratar do quilombo Palmares à exemplo da primeira grande organização social de uma população que foi, socialmente, designada à exclusão. De outra maneira, a comunidade de Palmares foi bastante influente na definição de um modelo de edificação para as primeiras favelas. Esses exemplos se relacionam tanto com os processos de dizimação do quilombo como processos diários de exclusão produzida pelos meios urbanos como novas formas de violência contra a população negra.

Porém, mesmo nesse cenário excludente e violento, é necessário verificar que há múltiplas relações acontecendo dentro das periferias. Se utilizando da obra Becos de Memória, é percebido que são desenvolvidos laços afetivos entre seus moradores, justamente pelo sentimento de pertença. Aliás, se desenvolve a narrativa que o futebol é um motor para aumentar esses laços afetivos, dessa forma, é utilizado a Liga da Canela Preta como exemplo entre as décadas de 1910 e 1920, como uma forma de organização autônoma da população negra, quando fora excluída da pratica do futebol nos clubes sociais da cidade.

${ }^{2}$ EVARISTO, Conceição. Becos de memória São Paulo: Contexto, 2017. 
Outra vez, fica demonstrado o caráter segregador, violento e preconceituoso do processo de formação social no país, são esses exemplos que serão explorados nesse artigo, pois é possível estabelecer uma relação entre esses momentos históricos e a forma como se perpetuam até hoje. De certa feita esse estudo tenta remontar esses fatos, além demonstrar a importância do futebol para as populações periféricas.

A análise será realizada através do referencial bibliográfico, já mencionado, de uma obra literária capaz de se conectar com as vivências das comunidades, ainda mais sob o olhar de uma autora tão importante para a literatura brasileira. Por se tratar de um romance memorialista, torna-se viva a relação de proximidade da literatura com a teoria na prática, interferindo na própria noção de realidade social retratada através das favelas. O referencial teórico também busca tratar de aspectos sociais das regiões que iniciaram os primeiros contornos da desigualdade no Brasil: as periferias. Situações, estas, não menos importantes que despertam uma profunda memória de coletividade e que serão discutidas em analogia com o futebol.

Esse estudo busca trazer essa relação de uma forma teórica, ao mesmo tempo em que considerará a forma como as relações acontecem dentro das comunidades. Por onde passam as singularidades e as formas de vida em particular. Não usaremos a fala de entrevistados nesta pesquisa porque optamos por respeitar a própria produção de saberes indisciplinados do sul global. Desta forma, esse estudo busca trazer ligações da práxis a uma forma de resposta teórica, ao mesmo tempo em que se aprecia as relações construídas entre as pessoas que vivem nas comunidades para fora desta. Optamos por não utilizar entrevistas como um fim, pois, compreendeu-se que desta forma, estaria se respeitando a própria produção de saberes, uma vez que a obra de Evaristo retrata justamente essa preocupação. Saberes diversos que são produzidos por outras formas alternativas à lógica da ciência, e para tal propósito, servem à colonialidade do saber-poder. A dedução que fazemos aqui é a de que a colonialidade-do-poder está atrelada a estruturas que refletem exemplares de autoridade. 
Nesse sentido, toda a forma de poder já está organizada pelo conhecimento colonizador, ou seja, por diferentes formas eurocêntricas de compreender e validar o mundo da vida e as suas relações sociais. Aliás, o mundo só poderá existir e funcionar dentro destas mesmas estruturas científicas. $O$ embate que se propõem retratar ocorre na interpretação do sujeito em desajuste, na tentativa de reformular essas estruturas estatais ou reconstruí-las de maneira diferente daquela que despreza outras formas de expressões, de linguagem, de pertencimento e outras experiências de organização, à exemplo das comunidades de periferia. Nesse sentido, a periferia é resistência epistêmica na produção de um saber oposicionista-cultural, onde o esporte é o seu espaço de fuga para tal expressão.

Diante disso, passaremos a considerar o esporte como um elemento funcional que contribui para amenizar dores subjetivas, morais, em situações e ambientes pelos quais os moradores das comunidades são vítimas das mais diversas formas de violência. É através do futebol que exploraremos como se estabelecem essas relações afetivas para superar preconceitos.

\section{Organização social do meio urbano, quilombo e favela}

A urbanização do mundo, um dos fatos mais notáveis dos tempos modernos, trouxe modificações profundas em praticamente todas as fases da vida social. As transformações, que antes podiam ser acompanhadas durante um período de cinquenta anos, manifestam-se hoje aos nossos olhos em poucos anos, talvez em alguns meses (DE LAUWE, 1967). De tal modo, é possível destacar a influência de grupos sociais de periferia na dinâmica desses movimentos evolutivos dos grandes centros urbanos.

O processo de socialização de indivíduos nos novos meios urbanos se opera, sob certos pontos de vista, com maior dificuldade do que nos meios tradicionais. Isso ocorre justamente por haver uma formação social heterogênea. Deve ser observada a evolução das necessidades, pois, há influência das condições de vida e dos novos modelos culturais. Novas imagens que modificam as aspirações da população (DE LAUWE, 1967). 
De Lauwe trabalha com a perspectiva que a evolução dos grupos locais sublinha a necessidade de encontrar novas realizações correspondentes às necessidades das pessoas que se transformam constantemente (...). No seio de tais grupos locais, no conjunto da cidade, vemos nascer e desenvolverem-se associações de tipos diversos, cada vez mais numerosos. Trata-se de associações esportivas ou culturais, de sindicatos que tem por finalidade a defesa dos interesses dos trabalhadores, dos inquilinos ou de outras categorias de pessoas (inclui-se associações familiares ou de grupos políticos). Tanto na evolução, quanto as particularidades desses movimentos que se observam no Brasil, é necessário realizar um recorte racial para uma análise mais condizente com a organização social brasileira. Dessa forma, podemos pensá-la na seguinte forma:

Os grupos étnicos não são menos difíceis de observar e analisar. Em alguns países, as tensões que existem entre os habitantes de origens diferentes são uma das chaves do equilíbrio dinâmico das relações sociais e da evolução das estruturas do conjunto. A coexistência desses grupos no espaço, o cálculo das distâncias sociais que os separam, podem ser objeto de pesquisas precisas. Em cada cultura, entretanto, esses estudos devem ser conduzidos levando-se em consideração as condições particulares da sociedade de que se trata (DE LAUWE, i967, p.i17).

Essas formulações teóricas são necessárias para sinalizar de que forma a organização do espaço urbano se dá, como ele se relaciona com as áreas de favela e de que maneira a permanência da população negra, se encontra perpetuada a esses espaços territoriais pela exclusão. Importa o contorno de como se organizam essas comunidades em um país que tem, em sua estrutura de fundo, a classe o elitismo, a exclusão, e as mais variadas expressões de discriminação racial. No Brasil, a formação de inúmeros quilombos como, por exemplo, o quilombo dos Palmares assemelha-se às primeiras formas de habitação que, mais tarde, irão inaugurar as primeiras favelas. Essa forma de organização social aconteceu de diferentes maneiras na América Latina. A forte herança escravagista permaneceu como referência de uma estrutura social voltada à exploração sacrificial da população negra e racializada (D'SALETE, 2017). Ou seja, servia-se da mesma lógica capitalista de exploração da força de trabalho. Fatos, estes, que geraram resistências em busca de territórios habitáveis nas lutas por liberdade. Os coletivos de pessoas escravizadas eram tratados da seguinte forma: 
Nomes diferentes têm identificado esses coletivos de escravos que se rebelavam. Na América espanhola: palenques e cumbes; na inglesa: marrons; na francesa: grand maroonage; no Brasil: quilombos e mocambos; seus membros eram chamados quilombolas, calhambolas ou mocambeiros (KLEIN, 1987).

Muitos estudos destacaram os quilombos como manifestações de resistência à escravidão. Eram espaços formados por pessoas aprisionadas que fugiam da convergência entre os trabalhos forçados e práticas de violência associadas à lógica da colonialidade. No quilombo, muitas comunidades negras encontravam formas alternativas de resistência política cultivadas no isolamento, longe da marginalização dos grandes centros urbanos.

A forma de organização social dos quilombos pode ser considerada um fenômeno que se rebelicavam não apenas contra os padrões de vida impostos pela sociedade oficial, mas também pela restauração dos antigos valores coloniais. Nesse sentido, as fugas eram, uma negação da sociedade oficial, que oprimia os negros escravos, minando a sua língua, a sua religião, os seus estilos de vida (CARNEIRO, I958). Palmares é conhecido como a comunidade quilombola mais notória da região da Serra da Barriga, à época, então considerada Capitania de Pernambuco. Atualmente, a região pertence ao município de União dos Palmares, no estado brasileiro de Alagoas.

O quilombo dos Palmares se apresentava como uma organização contraaculturativa, ou seja, era um movimento de resistência contrário à aculturação europeia contra a qual eram submetidos a população de origem racializada e escrava (REIS; GOMES, 1996). Conforme Abdias Nascimento, o exemplo de Palmares é retratado da seguinte forma na história do Brasil:

Lá pelos anos 1590 e pouco, alguns africanos escravizados no Brasil romperam os grilhões que os acorrentavam e fugiram para o seio das florestas situadas onde estão os estados de Alagoas e Pernambuco. Inicialmente foram uns poucos, pequeno bando de fugitivos. Porem o grupo cresceu pouco a pouco até se tornar uma comunidade de cerca de trinta mil rebeldes africanos, homens e mulheres. Estabeleceram o primeiro governo de africanos livres nas terras do Novo Mundo, indubitavelmente um verdadeiro Estado africano - pela forma de sua organização socioeconômica e política - conhecido na história como República de Palmares. (...) A Republica de Palmares, com sua enorme população relativamente à época, dominou uma área territorial de mais ou menos um terço do tamanho de Portugal. Essa terra pertencia a todos os palmarinos, e o resultado do trabalho 
coletivo também era propriedade comum. Os autolibertos africanos plantavam e colhiam uma produção agrícola diversificada, diferente da monocultura vigente na colônia; permutavam os frutos agrícolas com seus vizinhos brancos e indígenas. Eficiente organizados, tanto social quanto politicamente, em sua maneira africana tradicional, foram também altamente qualificados na arte da guerra (NASCIMENTO, 2019).

Havia muitas particularidades no Quilombo dos Palmares e nas formas de organização enquanto movimento de reafirmação da cultura e do estilo de vida africanos preservados (CARNEIRO, 1958). O quilombo, por sua vez, era composto por vários mocambos, ou seja, era integrado por vários núcleos de povoamento. De modo geral, era constituído por população quilombolas que tinha sido escravizada em fazendas locais das capitanias da Bahia e Pernambuco. Algumas, chegaram a reunir uma população estimada em 33 mil pessoas (D'SALETE, 2017). Palmares ainda é muito lembrado pela dimensão do conflito, embora seja mais impactante o fato de ter sido o primeiro grande movimento de resistência política e social das Américas, durante o período colonial, em entrevista Zezito de Araújo, professor de história e supervisor de Diversidade da Secretaria de Educação do Estado de Alagoas, afirma:

A Revolução Francesa é tida como o símbolo da liberdade, mas a luta de Zumbi aconteceu antes. Enquanto em Palmares tínhamos propriedade coletiva, produção para subsistência e para troca, na colônia tínhamos atividade agrícola para exportação e escravidão como base do trabalho. São sociedades opostas"3

O quilombo se relaciona com a favela na medida em que ambos são espaços alternativos de partilha. Espaços onde a população negra encontrou refúgio para tentar viver longe da violência, da qual eram submetidos. Ainda que no quilombo coexistisse em total autonomia com o resto da metrópole, por diversas vezes, existiram tentativas de extermínio quilombola. A favela era uma alternativa de subsistência frente a total falta de programas de inclusão social para as pessoas escravizadas, após-abolição da escravatura, em 1988. A diferença entre o quilombo e a favela é a de que o quilombo servia de abrigo ao não-aprisionamento dos negros livres e fugitivos. Já as favelas, ao longo do século XX, passaram de locais de resistência à locais escolhidos para fixar moradia.

3JORNAL NH < https://www.jornalnh.com.br/2017/II/noticias/pais/2198556-quilombo-dos-palmares-ereconhecido-patrimonio-cultural-do-mercosul.html>. Acesso em 13.12.2019. 
Assim, o quilombo e a favela foram defendidos como territórios que se fundam em relações de força (VITALINO, 2019).

As áreas urbanizáveis são dominadas pela especulação imobiliária, e, neste ambiente, a população de baixa renda não é considerada. Fato que essa população se organiza para ter um espaço de moradia. Uma pesquisa publicada no livro "Um País Chamado Favela" revela que $72 \%$ dos moradores se declararam negros (MEIRELLES; ATHAYDE, 2014). Tal acontecimento se dá pela formação e origem das favelas - a suposta libertação das pessoas escravizadas e a falta de condições para que pudessem de fato ter uma vida livre e terras para moradia.

Assim, comunidades informais crescem de forma silenciosa, gradual e orgânica, tornando-se difícil estabelecer o tempo exato em que um coletivo de barracos passava a se tornar uma comunidade autossustentável. Nessa mesma lógica, o crescimento silencioso é percebido pela favela através da "lógica quilombola" identitária, conforme é retratada durante a passagem do livro "Becos de Memória". Sobre a concepção da favela na memória popular, descreve-se:

Vinha sabendo onde iria ficar. Um amigo estava esperando por eles. Tinha dinheiro suficiente que dava para comprar um barraco. [...] Aqui na capital carece da gente aprender um modo novo de viver... Quando cheguei na favela, ainda tinha muito lugar vazio. Essa minha casa era só um quartinho, fui aumentando aos poucos. Hoje você vê, menina, são quatro cômodos; comecei com Nega Tuína (EVARISTO, 2017, p.89).

Como podemos ver, a favela é lembrada como um "lar", um lugar expressivo na forma como seus moradores a vêem. O fato de ter que abandonar a comunidade e os barracos - por mais pobres que fossem - inquietava, pois, era naquele espaço humilde e esquecido, que se deparam, os moradores, com sólidos laços de afeto comunitários. $\mathrm{Na}$ favela, se construíam relações sociais onde as histórias de vida passavam a serem contadas pela memória da oralidade. Por outro lado, essa realidade ressalta a concepção discriminatória de parte da população hegemônica das cidades em relação aos moradores da periferia. Lugares que, para outros tantos, não passam de um lugar insalubre e desorganizado, cujos moradores não passavam de entraves ao progresso e a lucro pela iniciativa da especulação imobiliária nessas áreas (LANGA, 2015). 
Embora desprovidas de qualquer ajuda governamental e de saneamento básico, a opção por residir nos centros urbanos era, entre os seus habitantes, uma questão de subsistência. Excluídos das vagas de trabalho formal pelo fato de importar mão-de-obra, a população negra procurava no mercado de trabalho dos portos, e residia nos lugares mais próximos de seus serviços (LANGA, 2015). Na obra "Becos da memória" um dos motivos que atemoriza os moradores que deixavam a favela era o fato de partirem para um espaço distante dos seus locais de trabalho: "Todos sabiam que a favela não era o paraíso, mas ninguém queria sair. Ali perto estava o trabalho, a sobrevivência de todos" (EVARISTO, 2017).

Nesse sentido, a noção de "enraizamento" cultural passa a ser questionada quando a iminência da perda do lar, de uma memória diaspórica, passa a ser problematizada como parte da visão de pertencimento que gera laços afetivos com o ambiente: "Quem disse que o homem não gostaria de ter raízes que o prendessem à terra?”. Em outra passagem, é destacado o tensionamento entre os moradores da favela e seus vizinhos ricos: "Respeitem nosso local, nunca venham com plano de desfavelamento, que nós também não arrombaremos a casa de vocês" (EVARISTO, 2017).

Nesse ambiente, em razão da possibilidade de desapropriação do poder público e da especulação imobiliária, diversas favelas foram removidas, fazendo da organização social um sentido amplo de disputa e de convivência entre as classes sociais no Brasil. Esse conjunto de diferenças e exclusões que o meio urbano, acaba revelando-se em um campo de pesquisa para compreender melhor esse fenômeno:

A harmonização dessas diferentes instituições no quadro do conjunto das estruturas sociais em transformação, na escala da cidade ou do bairro, pode ser também objeto de pesquisas por parte dos representantes das Ciências Humanas (DE LAWE, 1967, p. 123)

Embora a obra de Evaristo pretenda inspirar a realidade de uma favela fictícia, se percebe com clareza que as histórias ali presentes fazem parte do cotidiano das periferias. Ainda nesse ambiente de pertencimento, em destaque, há o crescimento do futebol no mesmo período de formação dessas organizações sociais. No cenário do Brasil pósescravagista, o nascimento do futebol na favela reúne o que há em comum entre o 
interesse pelo esporte, como forma de alento e prevenção à marginalidade. Isso representava o início de uma prática muito importante para as comunidades negras, nos grandes centros urbanos da periferia.

A seguir, abordaremos afinidades entre a periferia e o futebol tratando como exemplo a "Liga da canela preta" e sua predominância esportiva em Porto Alegre.

\section{Periferia, futebol profissional e futebol de várzea}

No Brasil, a tentativa de uma democracia racial no Brasil passou por implicações diretas na forma de organização social. Neste momento, passaremos a tratar como enfoque o preconceito e a discriminação relacionadas às estruturas de manutenção da desigualdade racial, como um problema que informa diferenças de classe. Dessa forma, denota-se que essa tese reforça o caráter dominante da elite brasileira por ampliar ainda mais sua influência e força de exclusão a outros segmentos da sociedade. Essa narrativa favorece o estabelecimento de uma sociedade sobreposta por tensões, que prega discursos democráticos, mas que tem como propósito diferentes tipos de discriminação (PEREIRA, 200I). O mito da "democracia racial"4 foi uma elaboração distorcida, criada para desenvolver um pensamento de pacto social brasileiro afim de ocultar problemas raciais. Tal narrativa foi e ainda é um expediente largamente utilizado pelas classes dominantes brancas. Como intérpretes desses casos, pode-se incluir as obras de Gilberto Freyre que desenvolveram a tese no imaginário do brasileiro para amenizar a violenta e opressiva realidade das relações raciais (COSTA, 1975)

Essa construção textual tem o intuito de revelar as facetas da exclusão da população negra na sua participação e protagonismo social. O futebol foi uma válvula de escape para essas populações marginalizadas e dominadas por uma elite branca, que nos

\footnotetext{
${ }^{4}$ A expressão “democracia racial” é atribuída à Gilberto Freyre, a penar de não ser facilmente encontrada em suas obras mais importantes, ou de não estar listada na literatura especializada a não ser tardiamente, nos anos 1950. No entanto, Gilberto Freyre não é o único responsável pelas ideias nem pelo seu rótulo. Freyre teria pronunciado em uma conferência: "Aspectos da influência da mestiçagem sobre relações sociais e de cultura entre portugueses e lusodescendentes”, em 1937, Lisboa, Portugal. Ver: Democracia Racial. GUIMARÃES. Antônio Sérgio Alfredo. Cadernos Penesb, Niterói, São Paulo. 2002.
} 
campos de futebol, evidenciava o negro como protagonista. Isso fez com que a sua relação com o futebol no Brasil crescesse em larga escala. No Brasil, acaba se dando pela própria forma como o futebol se popularizou, desde a sua chegada até os dias de hoje, pois, o futebol alimenta o sonho de uma parcela da população que enxerga nesse esporte, uma forma de ascensão social, uma maneira de ter momentos de lazer.

Sendo assim, é necessário remontar a vinda do futebol ao Brasil, reconstituindo como se deu a inserção desse esporte no Brasil, considerando que para analisar a segregação que os negros sofrem no futebol, faz-se oportuno estabelecer um ponto histórico inicial para se chegar até a liga da canela preta. O futebol no Brasil tem esse viés elitista, e muito em razão disso, a sua prática esteve condicionada a ser realizada em clubes sociais da elite brasileira. Ao longo do tempo, a prática esportiva excludente acabou isolando dos segmentos mais pobres da população predominante negra.

O futebol chega ao Brasil em meados de 1894 como Charles Miller5. Esse esportista acabou tornando-se um dos percursores de maior relevância prática desse esporte no Brasil (MILLS, 2005). Embora a sua participação tenha auxiliado para a criação da primeira liga de futebol no Brasil, este sempre esteve voltado ao acesso e o conhecimento entre as elites brancas. Negros não eram aceitos pelos clubes sociais para a prática do futebol (GUTERMAN, 2009). Após esse momento inaugural, começaram a surgir os primeiros clubes de futebol no Brasil ${ }^{6}$ e no cenário regional do Sul do país. Em Porto Alegre, a prática do futebol não apontou características diferentes na introdução desse esporte, equivalendo-se a outras formas de adaptação em outras regiões do país (incluindo as áreas de periferia). Nesse movimento de chegada do futebol ao Brasil, havia também uma transição social em curso, pois, ainda permaneciam latentes os reflexos do escravagismo no país. Com o fim da escravidão, do domínio do Império e da estratificação das relações de trabalho livre, antigos vícios aristocráticos foram preservados na

\footnotetext{
${ }^{5}$ Esportista brasileiro, considerado por muitos historiadores o "pai" do futebol e do rugby no Brasil, ou simplesmente o seu representante/dirigente.

${ }^{6}$ No livro “O futebol explica o Brasil: uma história da maior expressão popular do país, 2009”, Gutemann traz fotos da elite brasileira assistindo as primeiras partidas de futebol em São Paulo, que foi o berço do início da prática do futebol” (GUTERMAN, 2009).
} 
sociedade brasileira, mantendo-se rígidos o cenário cultural da diferença econômica que separava brancos e negros. A permanência de uma mentalidade escravocrata seguia em direção às práticas culturais e esportivas, e eram indissociáveis às formas de segregação social, baseadas em critérios descriminantes de raça e classe (GUTERMAN, 2009).

Assim, mesmo após a abolição da escravatura, a população negra recém liberta não tinha qualquer possibilidade de inserção na sociedade, o que tornava praticamente impossível recomeçar uma nova vida. Com o fim do escravagismo e das práticas aristocráticas fizeram que os negros não pudessem se inserir socialmente e até mesmo impossibilitados de vender sua força de trabalho (BALZANO, 20I0). Nessa seara, esses aspectos criaram e reforçam a prática de preconceito para a inclusão dos negros na indústria nascente e no setor de serviços, fatos que refletiram no futebol brasileiro.

Independente dos problemas de inclusão e de possibilidades de permanência de uma vida com certa uma liberdade, a blindagem das práticas esportivas visava resguardar exclusividade às elites brancas, reforçando o aspecto segregador, assim o futebol teve o condão de romper essa lógica elitista, segundo Soares:

[...] traz em si processos dramáticos e representativos de problemáticas centrais da sociedade. Inicialmente reduto exclusivo das elites, tal esporte rapidamente rompeu os círculos aristocráticos para ganhar as ruas e tornar-se entretenimento popular de largo alcance" (SOARES, 1998).

Vale destacar que a presença de jogadores negros nos clubes pequenos era tolerada pela elite branca desde que não interferisse na hegemonia branca dos clubes sociais. $\mathrm{Ou}$ seja, não era permitido a abertura do clube para que grupos sociais excluídos não pudessem ocupasse esses lugares. Essa lógica torna possível analisar a Liga Nacional de Futebol Porto Alegrense, conhecida como a "Liga da Canela Preta", uma vez que está situada dentro desse mesmo contexto histórico.

Nesse cenário, a Liga da Canela Preta foi criada como uma maneira alternativa de possibilitar a participação de atletas que não tinham possibilidade antes de participar da prática do futebol através dos clubes de estrutura elitista da época. A Liga da Canela Preta promoveu o ingresso de jogadores de classes populares mais pobres, principalmente, 
afrodescendentes. O Observatório Racial nos traz alguns elementos que listam os clubes que compunham a Liga, pois, a competição contava com nove times, todos organizados com diretorias, técnicos e sócios. Entre os disputantes, destacaram-se os times Bento Gonçalves e o Rio-Grandense. Participavam também os times: Primavera, o Primeiro de Novembro, Oito de Setembro, União, Palmeiras, Aquidabã e Venezianos. Todos estes oriundos da comunidade negra, como Cidade Baixa, Ilhota, Colônia Africana e Areal da Baronesa (OBSERVATÓRIO RACIAL, 2019).

O sucesso da Liga da Canela Preta inspirou a criação de uma nova liga na década de 1920, organizada pela Associação Porto-Alegrense de Desporto (APAD). Esta liga foi a segunda divisão do futebol em Porto Alegre a ser batizada, e passou a ser chamada de “Liga do Sabão". Destacava-se por permitir a participação esportiva de atletas negros e racializado em suas competições. Essa iniciativa começou a chamar a atenção dos clubes brancos que buscavam convencê-los para que ingressarem em seus times. Esse episódio colaborava para uma tentativa de esvaziamento das ligas autônomas, como ocorreu no caso da Liga da Canela Preta, que à época, já tinha torcedores, sócios e ótimos atletas compondo a federação.

Para que fosse mantida a hegemonia em disputa, a Liga voltada para a elite provocou um esvaziamento do quadro de jogadores-destaque da liga da Canela Preta. Mudanças foram refeitas no regulamento anterior, recuando no que havia sido proibido antes, em relação a participação de atletas negros nas competições. Dessa maneira, demonstrou-se que a política de segregação racial adotada pelos times de futebol no passado, aos poucos, passou a ser progressivamente extinta, junto da discriminação de atletas em práticas esportivas. No entanto, foram apagadas também enquanto evidências importantes sobre uma cultura de grande influência popular como é o futebol. Até os dias de hoje, a história da liga da Canela Preta permanece revelando estruturas raciais mais profundas que não foram completamente superadas dentro dos clubes (LUDOPEDIO, 2019). 
No momento que uma minoria se vê impossibilitada de realizar uma prática esportiva, ela acaba se organizando de forma autônoma para possibilitar o desenvolvimento do esporte. Buscavam-se alternativas de convivência para uma melhor organização e possibilidades de ascensão social. Além da criação de espaços de afeto e troca de experiencias, novamente o futebol desenvolveu um papel importante para auxiliar nessa demanda.

Nos trechos do livro "Liga da Canela Preta: A história do negro no futebol, revela como as práticas de preconceito eram comuns à época pós-abolição, e como os negros se organizaram para criar espaços de resistência, e até mesmo de ascensão social, através do futebol. Um dos momentos escolhidos para ilustrar essa situação foi uma coluna assinada por Lupicínio Rodrigues, onde ele explica o porquê é torcedor do Grêmio, embora o clube traga um passado elitizado de segregação racista, onde atletas negros eram impedidos de jogar com a camisa do clube. Lupicínio relata que o clube Rio-grandense fez um pedido para se inscrever na Liga hegemônica da época (na liga de brancos). O clube Internacional não aceitou a inscrição gerando assim um motivo para que os negros torcessem para o Grêmio. Assim diz Lupicínio:

Este sonho durou anos, mas no dia em que o Rio-Grandense pediu a inscrição na Liga, não foi aceito porque justamente o Internacional, que havia sido criado pelo "Zé Povo", votou contra, e o Rio-Grandense não foi aceito. Isto magoou profundamente os mulatinhos, que resolveram torcer contra o Internacional, e o Grêmio, sendo o maior rival, foi o escolhido para tal (SANTOS, 2018).

Esse trecho da entrevista publicada em uma coluna de jornal no ano de 1963 , demonstra como os clubes e as entidades de administração do esporte se utilizavam de formas para manter sua hegemonia. O time Internacional nega a participação do RioGrandense e acaba contratando jogadores negros para jogar no clube. Isso é, reforça-se o aspecto hegemônico que é exercido pelas grandes ligas e seus associados e a forma como eram excluídos os clubes fundados por lideranças negras.

$\mathrm{Na}$ mesma coluna, Lupicínio remonta o cenário racista da sociedade que criava mecanismos que proibiam a participação de atletas negros no esporte, tanto na prática como na participação do quadro social de um clube: 
O Grêmio foi o último time a aceitar a raça, porque em seus estatutos constava uma cláusula que dizia que ele perderia seu campo, doado por uns alemães, caso aceitasse pessoas de cor em seus quadros. Felizmente, essa cláusula foi abolida, e hoje tenho a honra de ser socio honorário do Grêmio e ter composto seu que público ao pé desta coluna (SANTOS, 2018).

Com essas negativas arraigadas ao preconceito racial, clubes foram criados por atletas negros que contavam com grande força e prestígio local. Alguns destes se destacaram e elaboraram a criação de clubes sociais independentes que, mais tarde, tornaram-se clubes de futebol. Esses clubes mantinham diversas ações destinadas a população negra, como por exemplo, a Associação de Amadores, que em dezembro de 1926 organizou jogos para beneficiar a Sociedade Religiosa Beneficente Africana. Essa mesma sociedade havia organizado uma quermesse no mesmo ano, no dia 13 de maio, e teve três dias de duração. Dessa forma, podemos perceber que a religiosidade de matriz africana fazia parte do futebol e das demais atividades sociais dos atletas negros (SANTOS, 2018).

Em outra passagem, demonstra-se que havia atividades de circulação de uma imprensa negra, providenciada a partir dos clubes de futebol que estreitavam laços da população negra espalhada no Rio Grande do Sul. Segue:

As vinculações políticas em defesa dos negros, a circulação nos mesmos espaços, os envolvimentos em projetos comuns, as ligações pessoais, afetivas e parentais, tudo aproximava o interior da capital. Cachoeirenses e porto-alegrenses, dentre outros cidadãos, aproximaram suas trajetórias, servindo como exemplos de protagonismo e ascensão social (SANTOS, 2018).

A escolha teórica por contar a história da liga da canela preta tem por objetivo criar um "pano de fundo" e designar exemplos de exclusão da população negra em todos os aspectos sociais. Com toda a violência sofrida, a comunidade negra se organizava socialmente e buscavam sempre alternativas para a subsistência destes através do futebol. O futebol é, portanto, uma forma de lazer, de promover momentos de convívio social. Por sua vez, também pode abrigar acomodações para se discutir interesses políticos que, com o decorrer dos anos, esse esporte acabou movimentando. O esporte está para a 
comunidade negra como uma possibilidade de venda da força de trabalho, dando margens à meios de alternativos de ascensão social.

Evidente que essa perspectiva trabalhada está imbricada ao futebol como política expropriatória de venda força de trabalho e de acumulação de capital. O futebol de várzea, por exemplo, é uma modalidade de futebol amador. Sua prática foi a que mais alimentou o futebol profissional brasileiro com o talento de jogadores de excelência. Com contrastes, a Favela e o futebol têm papel fundante na forma como se concebe e se consome o futebol hoje, pois, os jogadores brasileiros deram outra tônica ao esporte.

Em Becos de memória há um personagem identificado na obra como àquele que tinha uma relação muito comum com o futebol de várzea/amador nas periferias: o torcedor de várzea. Conceição Evaristo nos apresenta o personagem "Bondade", em uma passagem que retrata os festivais de bola e os eventos que contribuíam para alimentar o senso comunitário de pertença dos moradores:

Bondade adorava os festivais de bola. Não jogava, mas tinha o uniforme completo do time. Ele era uma espécie de talismã, era o 'pé de coelho' da moçada. Nos jogos em que o Bondade não aparecia podia-se saber que alguma coisa não sairia bem (EVARISTO, 2017).

Esse trecho é muito importante para demonstrar não só os laços afetivos, mas o sentimento de pertença que o futebol (ainda que amador) pode trazer. Esta ilustração deixa muito claro a importância que o campeonato amador representada para os moradores da favela. A mesma lógica é muito comum nas periferias brasileiras, pois, se trata de um espaço afetivo e de convívio com a população. Em outra passagem da mesma obra, Evaristo destaca a localização onde ficava o campo de futebol, no sentido de destacar o interesse desta realidade particular para as periferias:

Os festivais de bola na favela tinham gosto de grandes alegrias. Aconteciam em uma época certa, era uma vez por ano. Duravam meses, durante os sábados e domingos. O campo era uma área livre, enorme, que ficava entre a favela e o bairro rico. Bem rico e bem próximo. (..) No campo, a terra solta, durante os jogos, a cada chute de dado, levantava um redemoinho de pó, os jogadores caíam e rolavam na poeira. Em dias de chuva, caía-se na lama, às vezes até se machucava, mas a disputa continuava. Juntos estavam operários, os vagabundos, os marginais em hora de gozo e lazer (EVARISTO, 2017). 
Há uma riqueza de detalhes que remonta perfeitamente qualquer campo de várzea de uma periferia brasileira, como um espaço de criação de laços afetivos e de afirmação de pertencimento. É uma forma de ocupar um espaço de disputa, e essa disputa não é apenas territorial, mas uma forma de demonstração de força/superioridade cultural. Nos quilombos, o espaço não hegemônico não é elitista bem como a dinâmica de organização da liga da canela preta, conforme já mencionado em outro trecho, é trazida como o campeonato se organizava:

Em volta do campo fincavam-se bandeirinhas armadas em um varal de estacas de bambu. A garrafa de cachaça rolava de mão em mão, algumas cervejas também. Miúdos de porco eram sempre servidos. Muita gente criava porquinho no chiqueiro, no fundo do barraco. A bebida ficava sempre por conta daqueles que no momento tivessem mais. Donos de botequim e de bitaquinha sempre davam alguma. A criançada ganhava balas, pipocas e pirulitos (EVARISTO, 2017).

O destaque trazido agora demonstra o envolvimento da favela na organização e reforça o laço afetivo que as pessoas têm com o futebol de várzea. Algo que, quando comparado ao relato histórico da liga da canela preta, se parecem muito. Logicamente que a dinâmica urbana atual, praticamente, acabou com os campos de várzea. Hoje, são locais de disputa por espaços movimentados, envolvendo grandes valores imobiliários econômicos. Diante disso, esses eventos periféricos foram perdendo a sua essência, embora seja importante remontar essa relação entre a favela/periferia e o futebol, na atual organização urbana. Isso tira o espaço de mobilidade e ocupação das pessoas nas comunidades da periferia, além de promover processos de apagamento coletivos, situando os seus moradores cada vez mais à margem da sociedade. Todas essas iniciativas são identificadas como tentativas de desterritorialização das comunidades negras, e representam uma forma de privar momentos de pertencimento, de laços afetivos e de contatos com o espaço físico (de formas simbólicas e memorialistas), de incontáveis gerações de famílias.

\section{Considerações Finais}

Pensar a organização social do meio urbano no Brasil, pela ótica da obra Becos de Memória, é colocar a população negra como protagonista em um dos maiores 
movimentos contra-acultural na América: a constituição social dos quilombos. É importante ressaltar que essa autonomia comunitária, experimentada desde o formato dos primeiros quilombos, foi uma das grandes formas de organização social contrahegemônicas que as comunidades negras do nosso país produziram. Dessa maneira, é possível intuir proximidades paralelas entre a organização social e a dinâmica econômica dos quilombos, que influenciaram o propósito das primeiras comunidades. Em razão da preservação dos mesmos formatos coloniais, presentes na conservação das políticas autoritárias e racistas de Estado, o Quilombo dos Palmares foi dizimado e reconstruído cem vezes como símbolo de alteridade e libertação comunitária.

Tal fato acaba se perpetuando nas relações modernas urbanas, inclusive as violências submetidas a população negra como vítima diária da exclusão. Mesmo em um ambiente que sua população é, majoritariamente negra, destaca-se os diversos laços afetivos que as pessoas desenvolvem bem como o sentimento de pertença nas favelas.

Nesse sentido, a análise sobre o futebol e sua importância para os moradores das comunidades, majoritariamente negras, envolve ambientes abertos ao racismo em que seja possível fazer um novo paralelo da Liga da Canela Preta, organizada com a população periférica e negra de Porto Alegre. Mesmo quando eram impedidos de participar dos clubes sociais da cidade, essa população excluída acabara se organizando de formas autônomas para ter lazer e praticar o esporte. Assim, resta a evidência de que a importância e a sua influência na forma como se construiu o futebol no Brasil e a sua influência na forma de jogar no resto do mundo. A prática de futebol dentro das favelas e periferias no país, moldaram o esporte, moldaram a forma como se enverga e se consome o futebol hoje, e se estabelece como laços afetivos correlatos à demanda de reconhecimento público da exclusão racial. A escolha da produção literária de Conceição Evaristo nos guiou durante o enfrentamento dessas questões, reunidas à linearidade de importâncias que este estudo pretendeu aproximar sobre as comunidades negras.

Sendo assim, é possível perceber que mesmo em uma construção social violenta e segregadora, a população periférica de favela mostra que há, historicamente, uma 
afirmação cultural de pertencimento entre as suas práticas no futebol. Também demonstra como nos processos de formação social ainda se percebem como ambientes de exclusão e de segregação. Muito embora, saibamos, que nesse cenário de violência também existam laços afetivos e formas outras de subsistência em razão do pertencimento

\section{REFERÊNCIAS}

BALZANO, Otávio Nogueira. A retrospectiva histórica da discriminação e inserção dos jogadores de origem negra no futebol brasileiro EFDeportes.com, Revista Digital. Buenos Aires, Ano 15, № 149, outubro de 2010.

CAOS PLANEJADO. A diferença entra uma ocupação e uma favela. $<$ https://caosplanejado.com/a-diferenca-entre-uma-ocupacao-e-uma-favela-e-porqueisso-importa/> acesso em 13.12.2019.

CARNEIRO, Edson. O QUILOMBO dos PALMARES 2. COMPANHIA EDITORA NACIONAL ' SÃO PAUL O, Brasil. 1958.

COSTA, Emília Viotti. O mito da democracia racial no Brasil. Palestra proferida na reunião anual da Southern Historical Association, Washington, D.C., em I4 de novembro de 1975. Traduzido do inglês por Marco Aurélio Nogueira, 1975.

D’SALETE, Marcelo. Angola Janga: uma história de Palmares. São Paulo: Veneta, 2017.

DE LAUWE, Paul-Henry Chombart. A organização social no meio urbano. in: $O$ fenômeno urbano Org. VELHO, O. G. - Rio de Janeiro: 1967.

EVARISTO, Conceição. Becos de memória São Paulo: Contexto, 2017.

GUTERMAN, Marcos. O futebol explica o Brasil: uma história da maior expressão popular do país. - São Paulo: Contexto, 2009.

KLEIN, Herbert A demografia do tráfico de escravos no Brasil. Estudos Econômicos. São Paulo, 1987

JORNAL NH < https://www.jornalnh.com.br/2017/II/noticias/pais/2198556-quilombodos-palmares-e-reconhecido-patrimonio-cultural-do-mercosul.html>. Acesso em 13.12.2019.

LANGA, Ângela de Fátima. A RESSIGNIFICAÇÃO DEFAVELA EM BECOS DA MEMÓRIA: DA FAVELAFOBIA AO BECO-LAR. Revista Literatura em Debate, v. 9, n. 17, p. 80-95, dez. 2015. 
LUDOPEDIO. Apartheid gaúcho? A Liga da Canela Preta 〈https://www.ludopedio.com.br/arquibancada/apartheid-gaucho-a-liga-da-canelapreta/>, acesso em 13.12.2019.

MEIRELLES, Renato; ATHAYDE, Celso. Um país chamado favela: a maior pesquisa já

feita sobre a favela brasileira. São Paulo: Gente, 2014.

NASCIMENTO, Abdias. O quilombismo. O exemplo de Palmares. 3 ed. São Paulo: Editora Perspectiva. Ipeafro. 2019.

OBSERVATÓRIO RACIAL < https://observatorioracialfutebol.com.br/liga-dacanela-preta-conheca-o-campeonato-organizado-por-negros/ >. Acesso em 13.12.2019.

PEREIRA, Edimilson de Almeida e WHITE, Steven F. Brasil: Panorama de interações e conflitos numa sociedade multicultural. Rio de Janeiro, Afro-Ásia, 20or. p. 257-280.

Reis, João José e Flávio dos Santos Gomes. "Introdução: Uma história da liberdade". Liberdade por um fio. História dos quilombos no Brasil. Orgs. João José. Reis e Flávio dos Santos Gomes. São Paulo: Companhia das Letras 1996.

SANTOS, José Antônio. Liga da Canela Preta: a história do negro no futebol. Porto Alegre: Diadorim Editora, 2018.

SOARES, Antônio Jorge. Futebol, raça e nacionalidade no Brasil: releitura da história oficial. Rio de Janeiro, UFG, PP.EF. tese de doutorado, 1998.

VITALINO, Cláudia 〈https://vermelho.org.br/2012/o5/21/artigo-negros-sao-maiorianas-favelas $>$ Acesso em I4.12.2019 